\title{
The role of experience on techno-entrepreneurs' decision making biases
}

\author{
Pouria Nouri*, Behrooz Jamali and Ehsan Ghasemi
}

MS in Entrepreneurship Management University of Tehran, Tehran

\begin{tabular}{l}
\hline A R T I C L E I N F O \\
\hline Article history: \\
Received March 26, 2012 \\
Accepted 15 June 2012 \\
Available online \\
June 18 2012 \\
\hline Keywords: \\
Entrepreneurship \\
Entrepreneurial decision making \\
Biases \\
Overconfidence \\
Qualitative study
\end{tabular}

\section{Introduction}

Entrepreneurs show cognitive biases in their decision-making by not totally following rational decision-making models; they use mental and cognitive shortcuts (Baron, 1998). Using decision heuristics could lead to decision-making biases (Manimala, 1992). Entrepreneurs show different types of biases such as overconfidence, illusion of control, law of small numbers (Simon \& Houghton, 2003). Entrepreneurs are overly optimistic about their own chances of success (Cooper et al., 1988) and their over optimism sometimes leads to overconfidence bias. Managerial decisionmaking process doesn't follow rational models either. High costs of decision-making efforts (Simon et al., 1999), information-processing limits of decision makers (Abelson \& Levi, 1985), differences

\footnotetext{
* Corresponding author. Tel: +989122313702

E-mail addresses: pouria.nouri@yahoo.com (P. Nouri)

(c) 2012 Growing Science Ltd. All rights reserved. doi: 10.5267/j.msl.2012.06.026
} 
in the values of decision makers and a lot of reasons are the causes of the deviations from rational decision-making models. Opportunities are another factors resulting in possible decision-making biases. While discovery and exploitation of opportunities need significant amount of data and the information require to be processed soundly, entrepreneurs have neither enough time nor they need resources to complete such process and they even do not have to rely on their intuitions. Therefore, they become susceptible to biases in their decisions (Busenitz \& Barney, 1997; Forbes, 2005).

While entrepreneurs and non entrepreneurs are not differ in overall risk-taking propensities, they are differ in terms of how they think about business situations; entrepreneurs categorize these situations as having more strengths, opportunities and potential to gain than others (Palich \& Bagby, 1995). Uncertainty is the most important challenge they normally face and entrepreneurs try to overcome this hindrance by postponing their decisions until they have both enough information and necessary time to process the information. On the other hand, entrepreneurial intuitions grow in line with entrepreneurial experience. Intuitive decision-making is a very helpful approach under reverse circumstances such as high environmental novelty. The literature on entrepreneurial decisionmaking biases is divided into three distinctive categories:

Studying heuristics and their impact on decision making biases,

$>$ Studying major causes of decision making biases,

$>$ Studying major effects of decision making biases.

The main goal of the current study is to identify the main biases among Iranian techno-entrepreneurs and measuring the impact of experience as major individual factors on these biases. Data was collected for this study via some in-depth interviews with 25 techno-entrepreneurs. After analyzing the interviews elaborately, we came to the conclusion that overconfidence, illusion of control, planning fallacy and escalation of commitment are the main decision making biases among the interviewees, respectively, and the more experience could lead to more overconfidence . After a concise review of the literature and describing research method, we analyze the interviews with the entrepreneurs and at the end submit our findings, conclusions and recommendations.

\section{Literature review}

Opportunity recognition, opportunity evaluation and exploitation, resource allocation and resource combination to make new combinations, managerial capabilities, relative autonomy and risk taking propensity, lack of adequate time and resources, ambiguity, ambivalence and high environmental novelty are the most common characteristics in entrepreneurial decision-making atmosphere and process. Entrepreneurial decision-making is a multi-step, multi-characteristic process. It is the result of interaction among expectations of the future, information at hand and the evaluation and estimation of the information (Aldrich \& Zimmer, 1986).

A rational decision making process is the combination of enough information, the knowledge regarding the problem, sufficient and reliable alternatives and the comprehensive assessment of the alternatives. Environmental complexities and constant change could result in not fully rational decision-making. As the size and age of organizations and also the number of staff and employees grow, decision making becomes more rational and follows special rules and frameworks. In entrepreneurial, decision-making, the manager's and it's team's individual characteristics play major roles (Fresse et al., 2000).

In a rational decision making process, decision maker should fully consider all the facts and information available, needed time, market situation, competitors, possible losses and gains, should 
be fully considered and contemplated, then the decision could be made. This process usually will not more likely occur in the early years of business (Forbes, 2005).

Under severe circumstances, entrepreneurs use their own intuition, rely upon their personal judgment, do not search for alternatives and extra information and do not process the extra information, if available. Personal characteristics and market characteristics, the amount of investment, capital and psychological and cognitive determinants are among other factors influencing entrepreneurial decision- making environments. Considering all facts and circumstances, it could be hypothesized that entrepreneurs are prone to decision-making biases (Wells, 1974).

\subsection{Main entrepreneurial decision making biases}

A lot of entrepreneurial decision-making biases have been described, but in this section, we pay special attention to four biases identified among the interviews in our study.

1) Overconfidence: Overconfidence has been identified as one of the most common entrepreneurial decision-making biases. It refers to individuals' tendency to overestimate the correctness of their initial estimates in answering moderate to difficult problems (Bazerman, 1994). Overconfidence is common among entrepreneurs, managers, and bankers. Overconfidence have two different kinds (Cooper et al., 1988):

- Optimistic confidence and tendency to believe and hope that the desired results would occur.

- Exaggerating the amount and importance of one's knowledge and information.

2) Illusion of control: This bias occurs when entrepreneur overestimates the effect of his or her skill and expertise in situations where chance plays an important role, too. To overcome their anxiety and discomfort in unpredictable and tumultuous situations, people convince themselves that they can control and forecast the result of their predictions and decisions (Schwenk, 1985).

Managers and entrepreneurs with illusion of control may believe that they can predict the outcome of their decisions and the market situations and therefore could encounter their enterprises with risk (Schwenk, 1985). It must be noted that there is a significant distinction between overconfidence and illusion of control, while overconfidence refers to the overestimation of one's knowledge and information, illusion of control is about the overestimation of one's practical ability and expertise.

3)Planning fallacy: The propensity of the person to overestimate how much he/she can accomplish in given period of time or to underestimate the needed time to fulfill a specific project or assignment. When assessing the situation and anticipating the needed time to accomplish a project, people usually concentrate on the past and ignore their relevant experiences from the past, and tend to isolate the current situation from the past similar projects and situations. Therefore, they make themselves prone to planning fallacy (Kahneman \& Lovallo, 1993).

4) Escalation of commitment: Allocation of time money, and other resources to the plans that do not have good chances of success anymore. Feeling responsibility for the initial decision, the lack of willingness to begin the decision process all over again, concerns about one's face and credibility among staff and investors and strong wish to justify the initial decision are the main factors causing the bias (Bobocel \& Meyer, 1994).

All these four biases have, at least, one common feature: They could result in risk and therefore endanger the outcome of the enterprises. 


\subsection{Main causes of decision making biases}

The main factors influencing entrepreneurial decision-making biases are divided into three different categories. These categories are:

- Environmental factors, including environmental uncertainty, environmental novelty and highly environmental competition (Taylor, 1975).

- Organizational factors, including organization age and organization size and information overload (Forbes, 2005).

- Individual factors, age (Forbes, 2005), education (Baron, 1998), experience (Shepherd et al., 2003), gender, concentrating on the present and forgetting similar situations from the past (Kahneman \& Lovallo, 1993), emotions and cognitions are the main individual factors of decision-making biases among entrepreneurs.

There are some evidences that entrepreneurs' emotions affect their decision making process, significantly. They exhibit emotions, mostly because of their commitments to their own business (Baron, 1998). Emotions affect entrepreneurial decisions even if they are unrelated to the subject. Negative emotions cause avoiding behavior; increase their risk taking propensity and attention, helping them make better decisions (Schwarz et al., 1991).

Positive emotions on the other hand increase their optimism and willingness to take risks in the business and make them ignore some alternatives and decision consequences (Baron, 1998). Cognitions have some great effects on entrepreneurial decisions, too. People in general (and entrepreneurs particularly) tend to pay more attention to negative information, and to the information that somehow confirms their previous beliefs and knowledge. Entrepreneurs expect positive outcomes and events they search for positive information that corroborates their beliefs and ignore discrepant and negative information (Busenitz \& Barney, 1997).

\section{Research method}

In this paper, a qualitative approach was used by doing some in-depth interview with 25 techno entrepreneurs in Tehran, Iran. Our main goal was to identify the main decision-making biases and find out the impact of experience on these biases. We also use critical incident technique, by which the entrepreneur is asked to recount his/her most important, most decisive decision regarding his/her business. Interview questions were prepared according to literature review on entrepreneurial decision- making biases. Each interviewee was asked to recount his or her major decisions in the last three years regarding his or her enterprise, and then questions were directed to identify the biases in some decisions in some phases of the enterprise. For example in order to identify overconfidence, each entrepreneur was asked the following questions;

- Have did they try to gather extra information after having gathered the needed information?

- Have did they allocate time to process the extra information when available?

- Have did they have any remorse, regret or second thoughts after making decisions?

Entrepreneurs who do not gather extra information or do not have any second thoughts after making decisions are more overconfident. Overconfidence, illusion of control, escalation of commitment and planning fallacy were the identified biases among the interviewees. The interviewees' average age was 41.11 of them had master's degree or Ph.D. In order to measure the impact of experience; the interviewees were categorized based on definitions of GEM. According to GEM:

- New entrepreneur is somebody who has launched an enterprise, is the owner of that enterprise, the enterprise is not older than 42 months, and he has paid wages and salary to his employees not more than 42 months and not less than 3 months. 
- Established entrepreneur is someone who is the owner of an enterprise, is managing it, and that enterprise is at least 42-month-old.

Therefore, new entrepreneurs were considered inexperienced and established entrepreneurs were considered experienced entrepreneurs. According to these definitions, 5 of the entrepreneurs were new and the others were established entrepreneurs.

\section{Results}

\subsection{Data Analysis}

After gathering data by means of elaborate interviews, we used the method of Creswell (2005) to analyze it. The written statements information were summarized and categorized into shorter and more important statements (topics). In the final phase, we tried to identify the biases according to definitions in the literature reviews. By assessing verbal statements of the entrepreneurs we were be able to identify the main decision-making biases. Table 1 shows some entrepreneurs' verbal statements indicating decision making biases.

\section{Table 1}

A sample of entrepreneur's verbal statements

Bias Verbal Statements

"I trust my judgment and intuition, in case of high time pressure and

Overconfidence information overload or even reverse circumstances and crisis, my personal judgment has been my sole guide"

Illusion of control "In the beginning phases of my enterprise I used to suppose that I have control over all aspects of my firm, even reverse environmental conditions"

Escalation of "When I make a decision after considering and assessing all pros and commitment cons, I am personally reluctant to change it. I neither have time to begin the decision making process again nor do I want to distrust my initial judgment"

"I always stick to my initial decision, even if it doesn't seem

Overconfidence prosperous. Changing decisions (repeatedly) causes the entrepreneur to lose face, credence, reliability and (maybe) self-confidence”.

Table 2

The most decision biases identified with their frequency

\begin{tabular}{lcc}
\hline \multicolumn{1}{c}{ Bias } & Established entrepreneur & New entrepreneur \\
\hline Overconfidence & 9 & 1 \\
Illusion of control & 5 & 1 \\
Escalation Of Commitment & 2 & - \\
Planning Fallacy & 2 & - \\
\hline
\end{tabular}

\subsection{Findings}

According to our findings:

- Over confidence, illusion of control, escalation of commitment and planning fallacy were the most common biases among interviewees, respectively (Table 2).

- Because of it high frequency in contrast to other biases, overconfidence was the main bias to measure the impact of experience among inexperienced and experienced entrepreneurs, and more than half of experienced(established) entrepreneurs had shown overconfidence in some phases of their enterprises. 
- Experience had three distinctive impact on shaping the interviewee's overconfidence:

$\checkmark$ Not searching for extra information because of the reliance on past experience,

$\checkmark$ Not taking into account the gathered information because they believed their past experience could enable them to make sound decisions by considering scant, selected information,

$\checkmark$ Not reviewing or changing the taken decision, and not paying attention to consultation with others, because they thought their experience is more reliable that consultants.

- Experience has not any apparent impacts on the other biases. Therefore, we could not come to any conclusions.

- According to our findings by interviewing techno-entrepreneurs, we hypothesize that the more experienced entrepreneurs have, the more propensity to show overconfidence in some phases of their decision-making processes.

\section{Conclusion}

In the current research, at first, we studied the literature on entrepreneurial decisions and decisionmaking biases. Some biases occur more than others and some are more common and more important, like overconfidence bias. Each bias happens because of so many factors, some of which we did not know in the past and some we do. For example the overconfidence bias is caused (or reinforced) by age, information overload, optimism, and a lot of other factors, or the status quo bias is caused or reinforced by experience (Shepherd et al.,2003), firm's age and structure, manager's education and expertise (Geletkanycz, 2001).

These factors in general could be summarized into three separate categories: individual factors, organizational factors, and environmental factors. We tried to find out the main entrepreneurial decision making biases through a qualitative study. According to our findings, overconfidence, illusion of control, escalation of commitment and planning fallacy were the most common biases among the Iranian techno-entrepreneurs and experience could enhance the entrepreneur's overconfidence. Experienced entrepreneurs tend not to search for extra information, not to take into account the available information and not to regret their decisions. The literature on humans in general and entrepreneurial decision-making biases is rich, but the following topics could be recommended for the future studies and research in this field:

- Experience could have huge positive results on entrepreneur's assignments including decision making, for example it could be surmised according to our interviews that more experienced entrepreneurs are more resilient under reverse circumstances and make more accurate predictions and assessments. The positive outcome of experience on entrepreneur's decisions must be fully examined.

- This study was performed on techno-entrepreneurs. The hypotheses of the current study could be examined on other entrepreneurs.

- Experience has some effects on overconfidence according to our study. Because illusion of control has some huge similarities with overconfidence, it is highly recommended that the effects of experience on illusion of control be examined, as well.

- Some researchers believe that biases and their causes remain intact and don't change over time, on the other hand some important factors like age, experience and expertise change over 
time, therefore one could believe that biases change over time, too. There is not enough evidence and research in this regard.

- Escalation of commitment and status quo are two important entrepreneurial decision making biases and both are based on the entrepreneurs' reluctance and aversion to change their decisions and strategies. Shepherd (2003) concluded that experience has major positive effects on status quo bias. This conclusion could be examined for escalation of commitment, considering the similarities between them (Shepherd et al., 2003).

\section{Acknowledgment}

We would like to sincerely thank the entrepreneurs who participated in our survey and provided their insights. The authors would like to thank the anonymous referees for their constructive comments on earlier version of this paper.

\section{References}

Abelson, R.P., \& Levi, A. (1985). Decision-making and decision theory. In G. Lindzey and E.

Aldrich, H.E., \& Zimmer, C. (1986). Entrepreneurship through social networks. In D.L. Sexton Publishing, 3-23.

Bazerman, M. (1994). Judgment in Managerial Decision Making. Wiley Publications, New York.

Baron, R. A. (1998). Cognitive mechanism in entrepreneurship: Why and when entrepreneurs think differently than other people. Journal of Business Venturing, 13, 275-294.

Bobocel, D. R., \& Meyer, J. P. (1994). Escalating commitment to a failing course of action: Separating the role of choice and justification. Journal of Applied Psychology, 79(3), 360-363.

Busenitz, L.W, \& Barney, J.B. (1997). Differences between entrepreneurs and managers in large organizations: biases and heuristics in strategic decision-making. Journal of Business Venturing, 12, 9-30.

Cooper, A.C, Woo, C. Y., \& Dunkelberg, W.C. (1988). Entrepreneurs' perceived chances for success. Journal of Business venturing, 3(2), 97-108.

Forbes, D.P. (2005). Are some entrepreneurs more over confident than others? Journal of Business Venturing, 20(5), 623-640.

Geletkanycz, M.A., \& Blacks, B. (2001). Bounded by the past experienced based effects on commitment to strategic status quo. Journal of Management, (27) 3-21.

Gilbert, D.T. (1992). Blurry words and fuzzy deeds: The attribution of obscure behavior. Journal of Personality and Social Psychology, 62(1), 18-25.

Kahneman, D., \& Lovallo, D. (1993). Timid choices and bold forecasts: A cognitive perspective on risk - taking. Management science, 39 (1), 17-31.

Manimala, M.J. (1992). Entrepreneurial heuristics: a comparison between high PI and low PI venture. Journal of Business Venturing, 7(6), 477 - 504.

Palich, L., \& Bagby, D. (1995). Using Cognitive theory to explain entrepreneurial risk - talking: challenging conventional wisdom. Journal of Business Venturing, 10(6), 425 - 438.

Schwenk, C. (1985). Management illusions and biases, their impact on strategic decisions. Long Range Planning, 18(5), 74-80.

Shepherd, D.A., Zacharakis, A., \& Baron, R. A. (2003). VC'S decision process evidence suggesting more experience may not always be better. Journal of Business venturing, 18(3), 381-401.

Simon, M., Hougton, M., \& Aquino, K. (1999). Cognitive Biases Risk perception and venture formation: How individuals decide to start companies. Journal of Business Venturing, 15, 113134.

Simon, M., \& Houghton, S. (2003). The relationship between overconfidence and the introduction of risky products: evidence from a field study. Academy of Management Journal, 46(2), 139- 150. 
Taylor (1975). Age and experience as determinants of managerial information processing and decision making performance. Academy of Management Journal , 18(1), 74-81

Wells, W.A. (1974). Venture Capital Decision Making. unpublished doctoral dissertation Camegie Mellon University, PA. 